\title{
Os desenhos com raiva, de Italo Calvino, escritor de histórias para crianças
}

\author{
Eclair Antonio Almeida Filho
}

O escritor italiano Italo Calvino (1923-1985) é conhecido por ter desenvolvido, em suas obras, uma escrita lúdica, que visava, acima de tudo, divertir o seu leitor. Embora o universo da infância apareça em obras como A trilha dos ninhos de aranha (1947), Marcovaldo (1963) e no conto cosmicômico "Jogos sem fim" (1965), é apenas nas quatro storie per bambini (histórias para crianças) reunidas no volume 3 dos Romanzi e racconti (1994), a saber: Disegni arrabbiati (Desenhos com raiva), Il drago e le farfalle ( $O$ dragão e as borboletas), Le tre isole lontane (As três ilhas distantes), e La foresta-radice-labirinto (A floresta-raiz-labirinto) que Calvino escreverá diretamente para o leitor infantil.

Dessas quatro histórias para crianças, escolhemos traduzir "Os desenhos com raiva". Nesse conto que aqui apresentamos em tradução inédita, encontramos o Calvino escritor de histórias para crianças com sua linguagem lúdica, emblemática, numa trama que se desenrola e se narra através de um duelo por meio de desenhos que as crianças Lodolinda e Frederico fazem em resposta aos desenhos um do outro. Ao longo do conto esse duelo das crianças se mimetiza num duelo entre cowboys e índios pelevermelha, entre toureiros e touros, entre tigres e serpentes e águias, que surgem e tomam vida por meio da imaginação de Lodolinda e Frederico.

Em meu processo de tradução do conto calviniano, observei, principalmente, a questão do título e dos nomes, das referências culturais e da tensão entre a linguagem comumente associada a contos infantis e a linguagem do próprio Calvino. Por isso dei especial atenção à linguagem, que, segundo Regina Zilberman, na literatura para crianças serve como um "mediador entre a criança e o mundo, de modo que, propiciando, através da 
leitura, um alargamento do domínio linguístico, a literatura infantil preencherá uma função do conhecimento" (1984, p. 13)

Como título, preferi traduzir "I disegni arrabbiati" (literalmente 'os desenhos enraivecidos') por "Os desenhos com raiva", pois dizemos em português que "uma criança está com raiva" e não que "ela está enraivecida". Quanto aos nomes das crianças, mantive 'Lodolinda' por considerá-lo sonoro, ao passo que em relação a 'Federico' apenas o verti para o seu correspondente 'Frederico' em português. Para as referências culturais relativas às histórias de cowboys, traduzi os nomes conforme se convencionou no Brasil: General Custer (Generale Custer), Olho-de-Falcão (Occhio di Falco), Índios Pele-Vermelha (indiano pellerossa).

Para aproximar o texto da linguagem infantil, fiz uso do diminutivo como no seguinte trecho:

Quando se sente muito bem, desenha ovelhinhas que pastam entre as couves-flores, e quando se sente muito, mas muito bem, desenha ovelhinhas com patins de rodinha para que não parem de andar de uma couve-flor a outra. (Entre as ovelhinhas e as couves-flores deve existir certo parentesco, porque tanto umas quanto outras são desenhadas com linhas encaracoladas, assim como as nuvenzinhas. Quando Lodolinda começa um desenho com uma linha encaracolada $e$ ondulante, não se sabe nunca se ela está para desenhar uma nuvenzinha, uma ovelhinha ou uma couve-flor).

Quando si sente molto buona disegna pecorelle che pascolano tra $i$ cavolfiori, e quando si sente molto molto buona disegna pecorelle con i pattini a rotelle perché non si stanchino a camminare da un cavolfiore all'altro. (Tra le pecorelle e i cavolfiori ci deve essere una certa parentela, perché sia le une e sia gli altri si disegnano con delle linee ricciolute, come per le nuvolette. Quando Lodolinda comincia un disegno con una linea riccio-luta e ondeggiante, non si sa mai se sta per disegnare una nuvoletta, una pecorella o un cavolfiore).

Nesse trecho, traduzi 'pecorelle' por 'ovelhinhas', 'nuvolette' por 'nuvenzinhas', 'rotelle' por 'rodinhas'. Em relação a 'pecorelle' eu poderia ter também escolhido 'carneirinhos', que aparece em canções infantis brasileiras (carneirinho, carneirão...) e também na famosa estratégia de 'contar carneirinhos' para a criança dormir; mas preferi traduzir mesmo por 'ovelhinhas' que, a meu ver, se confundiriam mais com as couves-flores nos desenhos de Lodolinda. Ainda nesse trecho optei por traduzir 'molto molto' 
por 'muito, mas muito', forma que em português soa mais natural do que 'muito muito'.

Em relação à linguagem do próprio Calvino, ressalto como exemplo o trecho final em que o adjetivo 'prepotente' em italiano, comum-de-dois, não marca o gênero, por conseguinte, a identidade da criança que discute com a outra. Ao manter o adjetivo 'prepotente', sem me preocupar em encontrar um adjetivo que determinasse um gênero, o trecho em questão permaneceu na tradução sem uma identificação direta em relação a que personagem fala com a outra.

Por fim, tive uma preocupação em deixar bem naturais os diálogos entre Lodolinda e Frederico. Por isso, por exemplo, no seguinte trecho

- Copione! Sei un gran copione! Ecco cosa sei! - dice Lodolinda cercando di nascondere il suo disegno.

traduzi "copione" por "Seu imitão", de modo que o trecho ficou assim:

- Seu imitão! Você é um grande imitão! Isso é o que você é! - diz Lodolinda procurando esconder o seu desenho.

Assim, com esses procedimentos tradutórios, espero ter trazido para o leitor brasileiro um pouco do Italo Calvino escritor de histórias infantis. Agora vamos à leitura dos desenhos com raiva de Lodolinda e Frederico.

\section{Os desenhos com raiva}

Lodolinda é uma menina que ama muito desenhar.

Quando está de bom humor, desenha borboletas celestes e cor de laranja em cima de tulipas vermelhas e amarelas; quando está com raiva, desenha morcegos violetas e crocodilos verdes; quando tem vontade de chorar, desenha salgueiros chorões debaixo da lua.

Quando tem vontade de quebrar tudo, desenha um navio pirata que dispara um tiro de canhão contra uma torre na beira do mar, e a torre se despedaça em duas como uma casca de ovo.

Quando se sente muito bem, desenha ovelhinhas que pastam entre as couves-flores, e quando se sente muito, mas muito bem, desenha ovelhinhas com patins de rodinha para que não parem de andar de uma 
couve-flor a outra. (Entre as ovelhinhas e as couves-flores deve existir certo parentesco, porque tanto umas quanto outras são desenhadas com linhas encaracoladas, assim como as nuvenzinhas. Quando Lodolinda começa um desenho com uma linha encaracolada $e$ ondulante, não se sabe nunca se ela está para desenhar uma nuvenzinha, uma ovelhinha ou uma couve-flor).

Uma tarde os pais de Lodolinda saíram e deixaram a menina sozinha em casa com o filho de uns amigos seus, um menino que se chama Frederico. Para Lodolinda esse Frederico não é nada simpático. Primeiro ele quer botar os peixes vermelhos na lavadora de roupa para que eles saibam o que é uma tromba marinha; depois quer botar o gato no congelador para ver se ele resiste ao frio como um urso branco: como se não bastasse, quer passar o aspirador de pó na gaiola dos canários para representar um ciclone nas ilhas Canárias.

- Olha aqui: por que você não faz essas coisas na sua casa? - protesta Lodolinda, e ela tem muita razão.

Lodolinda não quer mais brincar com Frederico e por isso vai para o seu quartinho de desenhar. Já que está com muita raiva, desenha um touro enfurecido que abaixa os chifres e está partindo para o ataque. Depois resolve desenhar um toureiro que escapa, e este toureiro deve se parecer com Frederico. Nesse momento entra Frederico.

- Quero ver o que é que você está fazendo! O que é que você está fazendo? - diz Frederico. - Ah! Desenhos! Você me deixa desenhar com você? - e por conta própria já vai pegando umas folhas e uns lápis.

- Seu imitão! Você é um grande imitão! Isso é o que você é! - diz Lodolinda procurando esconder o seu desenho. - Sai daqui, vai, me deixa em paz, que eu quero terminar o meu desenho! - Nesse momento ela percebe que o seu desenho, que parecia estar tão bom, tinha ficado muito diferente de como ela pensava: o touro olha para cima com ar desesperado, e as patas se dobram como se estivessem para cair.

Lodolinda procura dar uma olhada na folha de Frederico, e o que ela vê? Frederico está desenhando um tigre, com as quatro patas para o ar como se estivessem pulando sobre a presa. Qual presa? Certamente o tigre de Frederico quer saltar sobre a garupa do touro de Lodolinda e por isso o touro está tão aterrorizado. Não há um minuto a perder! Lodolinda em alta velocidade se põe a desenhar na sua folha uma jiboia que mostra as suas peçonhas.

- O que está acontecendo com o meu tigre? - exclama Frederico. De fato para ele o tigre está ficando comprido e sutilmente fino como um 
tubo de pasta de dente apertado no meio, abrindo a goela como se estivesse não para morder, mas para sufocar.

Lodolinda está toda triunfante, mas Frederico já percebeu a serpente de Lodolinda que pode triturar o seu tigre, e se apressa em desenhar uma coruja com asas tão grandes e fortes, e garras tão afiadas, que ela pode muito bem levantar uma jiboia que está triturando um tigre que está despedaçando um touro.

Lodolinda se dá conta do perigo: vê as peçonhas letais da jiboia que pendem inertes como se fossem uma minhoca presa no anzol de um pescador. Assim que compreende que Frederico está desenhando uma coruja, tem uma ideia luminosa: desenha um cavalo morto de patas para o ar.

A coruja vai voar direto para onde ela sente cheiro de carniça e desistirá da serpente. Mas Frederico não é menos astuto do que Lodolinda: imediatamente desenha um tubo de desodorante spray que neutraliza 0 cheiro de carniça.

Lodolinda agora decide apostar todas as suas fichas: desenha uma flecha. Se a flecha atingir o pássaro em cheio, a jiboia poderá triturar o tigre, e salvar o touro. ( $\mathrm{Se}$, ao contrário, ela errar o alvo, poderá atingir o desodorante spray e afastá-lo de lá). A flecha é rapidamente desenhada, mas para que tenha alguma probabilidade de atingir o alvo ela deve ser atirada pelo arco do índio Olho-de-Falcão. Agora, cá entre nós, desenhar um índio pele-vermelha que estica o arco é algo tremendamente demorado e complicado. Enquanto isso, Frederico tem todo o tempo para desenhar o laço de um cowboy, capaz de apertar o braço do índio e desviar o tiro da flecha.

Lodolinda percebe que a sua flecha está saindo torta, e não lhe resta outra coisa senão fazer descer do alto das colinas uma tribo de índios a cavalo para libertar Olho-de-Falcão do laço do cowboy.

Mas Frederico já está pensando bem à frente: os índios estão se aproximando, mas se chegarem os reforços do general Custer, o cowboy estará salvo. O desenho que ele tem que fazer não é tão difícil como parece, porque quando «chegarem os nossos» a primeira coisa que todos vão ver será uma grande nuvem de poeira no horizonte. Por isso basta desenhar uma nuvem de poeira, e os índios - assim que a avistarem - baterão em retirada.

Dessa vez Lodolinda se sente mesmo perdida, porque quando «chegarem os nossos» a história simplesmente estará no fim. A menos que a televisão se danifique antes da palavra «Fim». E Lodolinda na sua folha traça tantas linhas horizontais ondulantes como quando uma tempestade 
de ondas magnéticas atrapalha a imagem da tela. Porém, Frederico aprendeu que se há um problema na televisão a cores, é só apertar um botão para passar para preto e branco. Desenha de novo a nuvem de poeira, mas agora em preto, que fica muito melhor do que antes. (Primeiro ele tinha desenhado a nuvem de poeira em azul e amarelo).

Lodolinda desenha um bisão.

Frederico desenha nuvenzinhas de poeira para que o seu cowboy escape.

Lodolinda queria cantar vitória, mas preferiu desenhar também umas nuvenzinhas de poeira mais leves para que Olho-de-Falcão pudesse se pôr a salvo. Uma bela confusão! Agora seu índio tem que se pôr a salvo de um bisão desenhado por ela mesma!

Então o índio e o cowboy escapam juntos. Lodolinda e Frederico se puseram a desenhar na mesma folha.

- Você desenhou o que agora? - pergunta Frederico.

- Um rio!

- E pra quê?

- Para não deixar o bisão passar!

- Brilhante ideia! E como nós vamos passar por ele?

- O cowboy joga a corda e aí puxa a gente até o outro lado do rio.

- O cowboy é meu!

- Sim, mas agora estamos escapando juntos.

- Eu vou desenhar é outra coisa. Olha aqui.

- O quê?

- Um curral.

- Ah não, só você acha que isso é um curral...

- Se eu estou dizendo que é um curral, é um curral, e aí o cowboy fecha a porteira e está a salvo.

- E o Olho-de-Falcão, vai deixar ele entrar?

- Bom, entra, mas bem rápido porque já está chegando o bisão.

Agora você tem que reforçar a porteira. Desenhamos tantas coisas pesadas umas em cima das outras: um colchão, um piano de cauda, um congelador... congelador?

- Pode me ouvir um pouquinho: você quer mesmo botar o gato no 
- Mas vai, você acredita em tudo que falam pra você!

Os pais de Lodolinda chegam em casa. - Nossa, mas que crianças admiráveis! Olha se não estão ali a desenhar bem tranquilas! - E os pais vão se sentar na sala de estar. Contudo, nem cinco minutos depois um estouro de berros faz os pais de Lodolinda se levantarem em sobressaltos.

- E eu vou desenhar um gato em cima do seu helicóptero!

- E eu vou desenhar um cachorro e aí faço o gato saltar no vazio!

- E eu vou desenhar um para-quedas!

- E eu vou desenhar um buraco no seu para-quedas!

- Prepotente!

- Ninguém pode brincar com você!

\section{I disegni arrabbiati}

Lodolinda è una bambina che ama molto disegnare.

Quando è di buon umore disegna farfalle celesti e arancione su tulipani rossi e gialli; quando è arrabbiata disegna pipistrelli viola e coccodrilli verdi; quando ha voglia di piangere disegna salici piangenti sotto la luna.

Quando ha voglia di rompere tutto, disegna una nave pirata che spara un colpo di cannone contro una torre sulla riva del mare, e la torre si spezza in due come un guscio.

Quando si sente molto buona disegna pecorelle che pascolano tra $i$ cavolfiori, e quando si sente molto molto buona disegna pecorelle con $\mathrm{i}$ pattini a rotelle perché non si stanchino a camminare da un cavolfiore all'altro. (Tra le pecorelle e i cavolfiori ci deve essere una certa parentela, perché sia le une e sia gli altri si disegnano con delle linee ricciolute, come per le nuvolette. Quando Lodolinda comincia un disegno con una linea riccioluta e ondeggiante, non si sa mai se sta per disegnare una nuvoletta, una pecorella o un cavolfiore).

Un pomeriggio i genitori di Lodolinda escono e lasciano la bambina sola in casa insieme al figlio di certi loro amici, un bambino che si chiama Federico. A Lodolinda questo Federico non è simpatico proprio per niente. Prima vuole mettere i pesci rossi nella lavastoviglie perché provino cos'è una tromba marina; poi vuole mettere il gatto nel frigorifero per vedere se resiste al freddo come un orso bianco: come se non bastasse, vuole passare l'aspirapolvere nella gabbia dei canarini per rappresentare un ciclone alle isole Canarie. 
- Senti: queste cose perché non le fai a casa tua? - protesta Lodolinda, e ha proprio ragione.

Lodolinda non vuole più giocare con Federico e se ne va nella sua stanza a disegnare. Siccome è molto arrabbiata, disegna un toro inferocito che abbassa le coma e sta partendo alla carica. Poi vorrebbe disegnare un torero che scappa e questo torero dovrebbe somigliare a Federico. In quel momento entra Federico.

- Cos'è che fai? Cos'è che fai? - dice Federico. - Ah! Disegni! Fammi disegnare anche a me! - e prende anche lui un foglio e delle matite.

- Copione! Sei un gran copione! Ecco cosa sei! - dice Lodolinda cercando di nascondere il suo disegno. - Lasciami in pace che lo devo ancora finire! - In quel momento s'accorge che il suo disegno, che le sembrava riuscisse così bene, è venuto molto diverso da come credeva: il toro guarda in su con aria spaventata, e le zampe gli si piegano come stesse per cadere.

Lodolinda cerca di dare un'occhiata al foglio di Federico e cosa vede? Federico sta disegnando una tigre, con le quattro zampe per aria come stesse balzando sulla preda. Quale preda? Certamente la tigre di Federico vuole saltare sulla groppa dei toro di Lodolinda e per questo il toro è così terrorizzato. Non c'è un momento da perdere! Lodolinda velocíssima si mette a disegnare sul suo foglio un serpente boa che avvolge le sue spire.

- Cosa succede alla mia tigre? - esclama Federico. Ill fatti la tigre gli sta venendo lunga e sottile come un tubo di dentifricio schiacciato nel mezzo e apre le fauci come se stesse non per mordere ma per soffocare.

Lodolinda è tutta trionfante, ma Federico s'è già accorto del serpente di Lodolinda che puo stritolare la sua tigre, e si affretta a disegnare un avvoltoio con le ali così grandi e forti e gli artigli così arcuati che puo beníssimo sollevare un serpente boa che sta stritolando una tigre che sta sbranando un toro.

Lodolinda s'accorge del pericolo: vede le spire micidiali del boa che pendono inerti come se fosse un lombrico appeso alI'amo d'un pescatore. Appena capisce che Federico sta desegnando un avvoltoio, ha un'idea luminosa: disegna un cavallo morto a zampe in su.

L'avvoltoio si precipiterà dove sente odore di carogna e trascurerà il serpente. Ma Federico non e meno furbo di lei: disegna un tubo di deodorante spray, che neutralizza l'odore di carogna.

Lodolinda gioca il tutto per tutto: disegna una freceia. 
Se la freccia colpisce l'uccello da preda, il boa potrà stritolare la tigre, e salvare il toro. (Se invece fa cilecca, potrebbe colpire il deodorante spray e toglierlo di mezzo). La freccia è presto disegnata, ma perché abbia qualche probabilità di colpire il bersaglio dovrebbe essere tirata dall'arco dell'indiano Occhio di Falco. Ora, disegnare un indiano pellerossa che tira l'arco è tremendamente lungo e complicato. Intanto Federico ha tutto il tempo di disegnare il lazo d'un cowboy, capace di stringersi al braccio dell'indiano e far deviare il tiro della freccia.

Lodolinda capisce che la sua freceia sta andando storta, e non le resta che far scendere dalla cresta delle colline una tribù di indiani a cavallo che liberino Occhio di Falco dal lazo del cowboy.

Ma Federico non sta a pensarci su: gli indiani stanno avvicinandosi, ma se arrivano i rinforzi del generale Custer, il cowboy è salvo. Il disegno da fare non è difficile come sembra, perché quando «arrivano i nostri» la prima cosa che si deve vedere è un gran polverone all'orizzonte. Dunque basta disegnare un polverone e gli indiani appena lo vedono batteranno in ritirata.

Stavolta Lodolinda si sente proprio perduta, perché quando «arrivano i nostri» la storia è bell'e finita. A meno che non si guasti il televisore prima della parola «Fine». E Lodolinda sul suo foglio traceia tante righe orizzontali ondeggianti come quando una tempesta di onde magnetiche sconvolge l'immagine del video. Ma Federico ha imparato che se c'è un guasto nella televisione a colori, si preme il tasto per passare sul bianco e nero. Ridisegna il polverone in nero e viene molto meglio di prima. (Prima l'aveva disegnato in blu e giallo).

Lodolinda disegna un bisonte.

Federico disegna delle nuvolette di polvere perché il suo cowboy scappa.

Lodolinda vorrebbe cantar vittoria, ma preferisce disegnare anche lei delle nuvolette di polvere piu leggere perché anche Occhio di Falco deve mettersi in salvo. Un bel pasticcio! li suo indiano che deve mettersi in salvo da un bisonte disegnato da lei stessa!

Adesso l'indiano e il cowboy scappano insieme. Lodolinda e Federico si sono messi a disegnare sullo stesso foglio.

- Cos'è che hai disegnato adesso? - chiede Federico.

- Un fiume!

- E a cosa serve? 
- Per non far passare il bisonte!

- Brava furba! E noi come lo passiamo?

- Il cowboy butta il lazo e passiamo appesi alla fune.

- Il cowboy è mio!

- Si, ma adesso stiamo scappando insieme.

- Invece io disegno un'altra cosa. Guarda.

- Cos'è?

- Un corral.

- Se credi che si capisce che quello è un corral ...

- Ti dico che è un corral e il cowboy chiude il cancello ed è in salvo.

- E Occhio di Falco non lo lasci entrare?

- Be', entra, ma fa' presto perché arriva il bisonte.

Adesso bisogna rinforzare il cancello. Disegniamo tante cose pesanti una sopra all'altra: un materasso, un pianoforte, un frigorifero...

- Senti un po', davvero volevi mettere il gatto in frigo?

- Ma va', credi a tutto quello che ti si dice!

I genitori tornano a casa. - Ma che bravi bambini! Se ne stanno li a disegnare tutti tranquilli! - $E$ i genitori vanno a sedersi in salotto. Ma non sono passati cinque minuti che uno scoppio di strilli li fa sussultare.

- $E$ io disegno un gatto sul tuo elicottero!

- E io disegno un cane e faccio saltare il gatto nel vuoto!

- $E$ io disegno un paracadute!

- E io disegno un buco nel paracadute!

- Prepotente!

- Con te non si puo giocare!

\section{Referências}

CALVINO, Italo. I disegni arrabbiati. In CALVINO, Italo. Romanzi e racconti vol. 3. Milano: Mondadori, 1994, pp. 347-351.

ZILBERMAN, Regina. O estatuto da literatura infantil. In MAGALHÃES, Lígia Cademartori. Literatura infantil: autoritarismo e emancipação. São Paulo: Ática, 1984. pp. 3-24. 